\title{
Visceral leishmaniasis and HIV coinfection: current perspectives
}

This article was published in the following Dove Press journal: HIVIAIDS - Research and Palliative Care

\author{
José Angelo Lauletta \\ Lindoso ${ }^{1-3}$ \\ Carlos Henrique Valente \\ Moreira ${ }^{1,4}$ \\ Mirella Alves Cunha ${ }^{5}$ \\ Igor Thiago Queiroz ${ }^{6,7}$ \\ 'Instituto de Infectologia Emilio \\ Ribas, São Paulo, Brazil; ${ }^{2}$ Nucleo de \\ Medicina Tropical, Universidade de \\ Brasília, Brasília, Brazil; 'aboratorio \\ de Soroepidemiologia, Institutode \\ Medicina Tropical, Universidade \\ de São Paulo, São Paulo, Brazil; \\ ${ }^{4}$ Laboratorio de Parasitologia, \\ Instituto de Medicina Tropical, \\ Universidade de São Paulo, São Paulo, \\ Brazil; ${ }^{5}$ Departamento de Infectologia, \\ Universidade Federal do Rio Grande \\ do Norte, Natal, Brazil; 'Universidade \\ Potiguar (UnP), Laureate International \\ Universities, Natal, Brazil; ${ }^{7}$ Hospital \\ Giselda Trigueiro (SESAP/RN), Natal, \\ Brazil
}

Correspondence: José Angelo Lauletta Lindoso

Instituto de Infectologia Emilio Ribas,

Avenida Dr Arnaldo 165, Cerqueira

César, CEP: 01246-000, São Paulo, Brazil

Tel +55 II 9 954I 6749

Email jlindoso@usp.br

\begin{abstract}
Visceral leishmaniasis (VL) is caused by Leishmania donovani and Leishmania infantum. The burden of VL is concentrated in tropical and subtropical areas; however, HIV infection has spread VL over a hyperendemic area. Several outcomes are observed as a result of VL-HIV coinfection. Impacts are observed in immunopathogenesis, clinical manifestation, diagnosis, and therapeutic response. Concerning clinical manifestation, typical and unusual manifestation has been observed during active VL in HIV-infected patient, as well as alteration in immunoresponse, inducing greater immunosuppression by low CD4 T-lymphocyte count or even by induction of immunoactivation, with cell senescence. Serological diagnosis of VL in the HIV-infected is poor, due to low humoral response, characterized by antibody production, so parasitological methods are more recommended. Another important and even more challenging point is the definition of the best therapeutic regimen for VL in HIV-coinfected patients, because in this population there is greater failure and consequently higher mortality. The challenge of better understanding immunopathogenesis in order to obtain more effective therapies is one of the crucial points to be developed. The combination of drugs and the use of secondary prophylaxis associated with highly active antiretroviral therapy may be the best tool for treatment of HIV coinfection. Some derivatives from natural sources have action against Leishmania; however, studies have been limited to in vitro evaluation, without clinical trials.
\end{abstract}

Keywords: visceral leishmaniasis, HIV infection, AIDS, diagnosis, therapeutic response

\section{Introduction}

Visceral leishmaniasis (VL) is a protozoan disease occurring, mainly in tropical and subtropical areas. The World Health Organization (WHO) estimates 200,000-400,000 VL cases and 20,000-40,000 deaths per year. The last WHO data from 2015 reported $>90 \%$ of new cases occurred in seven countries: Brazil, Ethiopia, India, Kenya, Somalia, South Sudan, and Sudan. ${ }^{1}$ Despite the burden of VL, there has been a reduction in the number of cases in some endemic countries, with Bangladesh achieving a significant reduction in new VL cases, with a clear proposal to eliminate transmission by 2020 . On the other hand, other endemic countries maintain a plateau of VL cases, eg, Brazil, which presents an annual average of 3,800 new cases. ${ }^{1}$

VL is caused by different Leishmania spp. in different geographical areas. In Indian, Nepal, Sudan, South Sudan, and Ethiopia VL is caused by Leishmania donovani, presenting an anthroponotic cycle where the human is the reservoir. In Brazil, VL is caused by Leishmania infantum, presenting a zoonotic cycle where dogs are the main reservoir. ${ }^{2}$ Both L. donovani and L. infantum are transmitted by Phlebotomus spp.; 
however, transmission by contaminated blood is reported, mainly in HIV-infected patients when syringes are shared by intravenous users of illicit drugs.

According to the WHO, in 201636.7 million people were living with HIV - 25.6 million in Africa, 3.3 million in the Americas, 3.5 million in Southeast Asia, 2.4 million in Europe, and 1.4 million in the Western Pacific - with 1 million deaths caused by AIDS. In those countries where VL burden is higher, the number of people living with HIV is variable. In Ethiopia, it was estimated in 2016 to be $710,000(570,000-$ $880,000)$, in India 2,100,000 (1,700,000-2,600,000), in Brazil 830,000 (610,000-1,100,000), in Kenya 1,600,000 (1,400,000-1,800,000), in Somalia 24,000 (16,000-33,000), in South Sudan 200,000 (130,000-290,000), and in Sudan 56,000 (34,000-87,000). ${ }^{3}$ An overlap between VL and HIVtransmission area can clearly be observed. Leishmania-HIV coinfection has been reported from 35 endemic countries. ${ }^{1}$ VL interacts with HIV infection, as HIV-infected people are particularly vulnerable to VL, while VL accelerates HIV replication and progression to AIDS, posing a major challenge in areas where there is a high coinfection rate.

In the early 1990s, increased incidence of VL-HIV coinfection in the Mediterranean basin was observed. Cases peaked in 1997, and after that (1998-2001) a plateau was observed. ${ }^{4}$ Since 2001, there has been a progressive decrease in VL-HIV cases in the same region, mainly due to the use of highly active antiretroviral therapy (HAART). Nowadays, the incidence of VL-HIV in the Mediterranean basin is very low. ${ }^{4}$ On the other hand, we observed an increase in VL-HIV coinfection in other geographical areas, particularly northwest Ethiopia, where incidence rates of VL-HIV coinfection are very high. ${ }^{5}$ In Latin America, mainly in Brazil, VL-HIV coinfection has steadily increased. Currently, the prevalence of HIV infection in patients with VL is $9 \% .{ }^{6}$ However, it is noteworthy that around $40 \%$ of patients with VL have no serology for HIV. Moreover, this percentage refers only to cases with clinical manifestation of VL. This would be the tip of the iceberg, since asymptomatic infection is common, and as a result of immunosuppression, which occurs in HIV infection and also in Leishmania infection, there may be recurrence and these patients may also serve as reservoirs for Leishmania. ${ }^{7}$

In a cohort of patients living with HIV, we observed a frequency of Leishmania infection that varied from 3\% to $25 \%$, depending on the serological method used to determine Leishmania infection (personal communication). Latent infection of VL in HIV-infected patients has been noticed, so people living with HIV have a high risk of VL progression when Leishmania-infected. ${ }^{8}$ This point could be better explored, because if patients present a decrease in $\mathrm{CD}^{+}$cell counts $<200$ cells $/ \mathrm{mm}^{3}$, clinical manifestation of VL is more common. ${ }^{9}$

Concerning asymptomatic VL-HIV, a major problem concerns the preemptive treatment of these patients, since there is no support in the literature that indicates the treatment of asymptomatic ones, even if they are at risk of developing manifestations of VL. A strategy of screening HIV-infected patient and treating them for leishmaniasis is not recommended. VL-HIV coinfected patients are at increased risk of relapse and higher lethality. This is clearly determined by the preponderance of the immunoresponse, mainly determined by $\mathrm{CD}^{+}$T-lymphocyte count. ${ }^{10}$

\section{Immunoresponse in VL-HIV- infected patients}

Depletion of the immune system induced by HIV infection and its virus-mediated immunoactivation, ${ }^{11}$ especially a decrease in the number of $\mathrm{CD}^{+} \mathrm{T}$ lymphocytes, allows the development of VL once those cells are responsible for parasite control. Immunosenescence is detected, which is characterized by exhaustion of immune resources and presence of the $\mathrm{CD} 57^{+} \mathrm{CD} 27^{-}$phenotype among senescent $\mathrm{CD}^{+}$and $\mathrm{CD}^{+} \mathrm{T}$ cells, promoting an accelerated decline of immune-system competence. ${ }^{11,12}$ Also, chronic immunostimulation induced by Leishmania enhances the multiplication of HIV and further progression of HIV infection to AIDS, depressing immunity by exhaustion of immune resources. ${ }^{11,13,14}$ Therefore, Leishmania-HIV coinfection has negative effects, generating poor outcomes and higher risk of relapse in coinfected patients. Even after successful treatment and HAART use, coinfected individuals present increased levels of $\mathrm{CD} 38^{+} \mathrm{CD} 8^{+} \mathrm{T}$ lymphocytes (pointing to increased cellular activation) and proinflammatory cytokines (MIF, MIP1 $\beta$, TNF, IL6, IL8, and IL17). In this way, they have chronic immunoactivation induced by persistence of parasites and/or by microbial translocation though the intestinal barrier, demonstrated by the presence of elevated levels of lipopolysaccharide, soluble CD14, and IFBP in serum levels, the immunopathogenic basis of which could be related to mucosal invasion by amastigotes and systemic lymphocyte depletion. ${ }^{13,15}$

Persistence of the parasite in coinfected patients suggests tolerance of the immune system, as the pathogen promotes immunosuppression actively by depressing host immunity. ${ }^{16}$ In infected cells, Leishmania causes an overexpression of CCR5, a coreceptor for HIV entry into $\mathrm{CD}^{+}$and $\mathrm{CD}^{+} \mathrm{T}$ lymphocytes, allowing an increasing in HIV viral load and consequently acceleration of disease progression of HIV 
infection and immunosuppression. ${ }^{16}$ Also, coinfected patients have a higher expression of inhibitory molecules in $\mathrm{CD}^{+}$ T-cell surfaces, hampering the equilibrium between T-regulatory cells and immunoactivation and allowing persistence of residual parasite burden, even after successful treatment for leishmaniasis. In addition, coinfected patients show lower levels of naïve $\mathrm{CD}^{+}$and $\mathrm{CD} 8^{+} \mathrm{T}$ cells than non-VL $\mathrm{HIV}^{+}$ immunological responders and nonresponder controls, but with a balanced increase in central memory $T$ cells, suggesting poor renewal of the T-cell repertoire or consequences of infection in the bone marrow by Leishmania. ${ }^{16}$

\section{Clinical manifestations}

Clinical manifestations of coinfected patients are similar to those of immunocompetent ones. ${ }^{12,17}$ However, as coinfected patients have some particular immunological characteristics, clinical manifestations of these patients may differ from those not infected with HIV, becoming a challenging diagnosis because of a similarity with other opportunistic infections. Sometimes, instead of presentation of classical symptoms, such as fever, pallor, and hepatosplenomegaly in immunocompetent individuals, coinfected patients present weakness, cough, diarrhea, undernourishment, and weight loss to a greater proportion than the former. In addition, hepatosplenomegaly and fever occur less frequently, while gastrointestinal symptoms are more frequent in the coinfected. ${ }^{12,18}$ Hemorrhagic phenomena occurs in almost a third of the patients, as lymph-node enlargement is also observed in the coinfected. ${ }^{19}$ When coinfected patients present to clinical settings with amastigotes in unusual sites (gastrointestinal and oral mucosa, skin, pleura, pericardium, lymph nodes, Kaposi's sarcoma lesions, and the respiratory tract), atypical manifestations are frequently observed. ${ }^{20}$ This fact contributes to misdiagnosis with other opportunistic infections or latter diagnosis of VL, culminating in poor outcomes for the coinfected. ${ }^{17,21}$ Consequently, as coinfected patients have a delay in their diagnosis of VL, lethality and relapse are higher than in non-HIV patients, as shown in Latin America by Lindoso et al, where lethality was $8.7 \%-23.5 \%$ and relapses $10.0 \%-56.5 \%$ of cases. ${ }^{12}$ In another study, Cota et al demonstrated similar results for coinfected patients: lethality of $6.6 \%$ and relapse rate of $37 \% .^{22}$

\section{Diagnosis of VL}

Many advances and the emergence of new methods have been observed in laboratorial diagnosis of VL. Nevertheless, the methodological heterogeneity of studies associated with geographical and etiological differences have contributed to a difficulties analysis in the lab. Furthermore, there is little information about the performance of laboratory techniques for VL diagnosis in HIV-infected patients. Parasitological diagnosis remains a good alternative, because of its easy execution and high specificity. As in immunocompetent patients, samples from lymph nodes, bone marrow, and spleen can be used for microscopic demonstration of amastigotes. ${ }^{23}$ Although spleen aspiration has better sensitivity, bone-marrow aspiration shows relatively good sensitivity and lower risk of bleeding complications. ${ }^{24}$ Few studies have analyzed the sensitivity and specificity of direct exams in HIV patients, due largely to the lack of a gold standard to compare the data. In a study performed in Brazil, Cota et al found the sensitivity and specificity of parasitological exams were $93.2 \%$ and $100 \%$, respectively. ${ }^{25}$ The sensitivity of direct examination using bone-marrow aspiration has been better than classical methods in the majority of studies, including in immunocompetent patients. HIV-infected patients have an increased parasitic load due to impairment of the immune system, which could explain the better results. In consideration of these data, especially in poor locations, where methods that are more modern are expensive and unavailable, parasitological methods are an excellent option.

Regarding serological methods, there is also a limitation related to heterogeneity of studies, including different antigens and geographical areas. In HIV-infected patients, due to dysfunction of T and B lymphocytes, serological tests have recognized low sensitivity. ${ }^{25-27}$ Some antigens and methods have better performance than others. Cota et al observed that the direct agglutination test and immunoblotting had better sensitivity ( $81 \%$ and $84 \%$, respectively) compared to ELISA and the immunofluorescence antibody test. ${ }^{26}$ However, few studies were included, and more data are necessary to establish a reliable serological test in HIV-infected patients. Recombinant antigens have been tested in different situations, both with ELISA and rapid tests. The most frequently used is the rK39 antigen, especially in immunochromatographic tests. Its use is already a reality in many parts of the world, showing sensitivity and specificity of $93 \%-98 \%$ and $98 \%-100 \%$, respectively. ${ }^{28}$ Nevertheless, the sensitivity of tests using this antigen, both ELISA and immunochromatographic, has been inferior in HIV-infected patients. ${ }^{25,29}$ Other recombinant antigens have been developed for diagnosis of VL, like rK28. Rapid tests using rK28 have demonstrated high sensitivity and specificity for VL diagnosis in the immunocompetent ( $92 \%$ and $100 \%$, respectively). ${ }^{30}$ However, there were no data on their performance in HIV-infected patients. Therefore, although there is reduced sensitivity with serologi- 
cal tests in HIV-infected patients, it is possible to use them to diagnose VL in this context. However, more studies are necessary to establish what is the better method and antigen. Another perspective is the use of methods to detect antigens, ${ }^{31}$ since HIV-infected patients have a larger parasite burden. Nevertheless, the studies on coinfected patients were small and preliminary results discordant. ${ }^{32}$

Methods based on molecular diagnosis are very promising in both the immunocompetent and HIV-infected. In general, they have great sensitivity and specificity and can be performed with a variety of samples: bone marrow, lymph nodes, spleen, and peripheral blood. PCR is the main method, with great sensitivity and specificity. PCR performance depends on the samples and primers used to amplify the DNA sequence. Amplification of kDNA regions seems to be a good option and likely the most sensible target DNA. ${ }^{33}$ Khatun et al used a primer $(\mathrm{MK} 1 \mathrm{~F} / \mathrm{R})$ for targeting of $\mathrm{kDNA}$ sequences, showing $100 \%$ specificity and $98 \%$ sensitivity in detecting VL using blood samples. ${ }^{34}$ Real-time PCR is another method for VL diagnosis in HIV-infected patients. ${ }^{25,26}$ As for other methods, studies evaluating performance of molecular methods in HIV-infected patients are scarce (Table 1).

\section{Treatment of VL-HIV coinfection}

One of the most challenging fields regarding VL-HIV coinfection may be the therapeutic approach, due the scarcity of data, for which the majority of clinical research has been carried out only in East Africa and Europe, resulting in limited external validity. In addition, major issues that include increasing widespread resistance to the most available drugs, pentavalent antimonial compounds, high treatment failure, toxicity, and relapse rates persist. ${ }^{35}$ Gaps remain for results from new or ongoing research, such as the optimal drug, dosage, and time for treatment and prophylaxis and the efficacy of combined therapies for the coinfection. ${ }^{36}$ Meanwhile, depending on Leishmania spp., local resistance patterns, geographical region, and current patient immune status, the drug of choice may change.

\section{Pentavalent antimonials}

These have been used for the treatment of VL since the 1940s. ${ }^{35}$ The two main agents are meglumine antimoniate (Glucantime [Aventis]) and sodium stibogluconate (SSG; Pentostam [GlaxoSmithKline]) are the most used compounds and considered prodrugs. ${ }^{36}$ Their parasitological activity may be due to the conversion to an active trivalent-antimony form, also associated with their toxicity, and it has been suggested that their leishmanicidal activity may occur by the inhibition of parasite ADP phosphorylation, topoisomerase I activity, and trypanothione reductase, which consequently inhibits glycolytic activity and oxidative pathways of fatty acids..$^{37,38}$ As Leishmania spp. lack alternate antioxidative machinery to resist lethal host oxidative stress, trypanothione reductase presents a great potential drug target. ${ }^{39,40}$ Efficacy of this drug class in most of published studies has generally been reported as low in the specific VL-HIV population, though widely ranging from $33 \%$ to $82 \%$, with high relapse rates. ${ }^{41,42}$ In a retrospective study with SSG for VL-HIV coinfection in Ethiopia, a cure rate of only $43.9 \%$ was reported at the end of treatment, although $21.1 \%$ of patients discontinued treatment

Table I Main methods used for the diagnosis of visceral leishmaniasis in patients coinfected with HIV according to sensitivity and specificity

\begin{tabular}{|c|c|c|c|c|}
\hline Laboratory method & Brief Description & Sensitivity & Specificity & Comments \\
\hline $\begin{array}{l}\text { Microscopic } \\
\text { examination (bone- } \\
\text { marrow aspiration) } \\
\text {-Giemsa staining }\end{array}$ & $\begin{array}{l}\text { Microscopic demonstration of } \\
\text { amastigote forms }\end{array}$ & $93.2 \%$ & $100 \%$ & $\begin{array}{l}\text { Not expensive; invasive method; great specificity and } \\
\text { sensitivity }\end{array}$ \\
\hline DAT & Agglutination serological test & $81 \%$ & $90 \%$ & Better performance of serological methods \\
\hline rk39 rapid test & $\begin{array}{l}\text { Immunochromato-graphic test using } \\
\text { recombinant } \mathrm{K} 39 \text { antigen }\end{array}$ & $46.6-81 \%$ & $96-100 \%$ & Easy and rapid method; great sensitivity and specificity \\
\hline ELISA & $\begin{array}{l}\text { Enzyme immunoassay using total } \\
\text { antigens }\end{array}$ & $50-60 \%$ & $90 \%$ & $\begin{array}{l}\text { Easy method; variable sensitivity and specificity, } \\
\text { depending on antigens; positivity in asymptomatic } \\
\text { individuals from endemic area }\end{array}$ \\
\hline IFAT & $\begin{array}{l}\text { Immunofluorescence to detect } \\
\text { antibodies anti-leishmania }\end{array}$ & $51-61 \%$ & $93 \%$ & $\begin{array}{l}\text { Easy method; variable sensitivity and specificity, } \\
\text { depending on antigens; positivity in asymptomatic } \\
\text { individuals from endemic area }\end{array}$ \\
\hline PCR & $\begin{array}{l}\text { Molecular method using specific } \\
\text { targets }\end{array}$ & $87.2-98 \%$ & $96 \%$ & $\begin{array}{l}\text { High sensitivity and specificity; not available in all } \\
\text { regions; frequently expensive }\end{array}$ \\
\hline
\end{tabular}

Abbreviations: DAT, direct agglutination test; IFAT, immunofluorescence antibody test. 
due to toxicity. ${ }^{42}$ These drugs should not be used in VL-HIV coinfection, because of the higher and potentially fatal toxicity in this population, although in areas of no significant resistance and when lipid formulations of amphotericin B are unavailable or unaffordable, it may be used. ${ }^{43}$ Death rates during treatment have been four- to tenfold higher compared to HIV-negative patients. ${ }^{44,45}$ Toxicities are directly related to the increase in the dose and manifested by severe vomiting, arrhythmia, and pancreatitis, in addition to emerging drug resistance. ${ }^{46,47}$ Increased failure rates have been reported in Bihar, India $-59 \%$ in a recent retrospective study, though this included non-HIV-infected patients - and it is interesting to mention that these high rates were associated with higher environmental arsenic exposure among the local population (Table 2). ${ }^{48}$

\section{Amphotericin (amphotericin B deoxycholate/liposomal/lipid formulations)}

Liposomal amphotericin B (LAmB; AmBisome, Gilead) consists of amphotericin B packaged with cholesterol and other phospholipids within small unilamellar liposomes in which better stability in blood, macrophages, and tissue is gained, leading to more effective drug levels and penetration, especially in liver and spleen. In addition, there is increased affinity for ergosterol and its precursors, and by contrast reduced affinity for mammalian cell membranes due to the cholesterol component, thereby decreasing toxicity. ${ }^{49}$ It is the major drug used, with better outcomes, in coinfected LV-HIV and the most potent leishmanicidal agent commercially available, acting both promastigotes and amastigotes by linking to esters of plasmatic Leishmania membrane. ${ }^{50,51}$ Although based on scarce scientific evidence, its safety profile has led to recommendations by the $\mathrm{WHO}$ and other international organizations as the preferred treatment for LV-HIV. ${ }^{52}$ The WHO guidelines recommend lipid formulations infused at a dose of $3-5 \mathrm{mg} / \mathrm{kg}$ daily or intermittently for ten doses (days $1-5,10,17,24,31$, and 38) up to a total dose of $40 \mathrm{mg} / \mathrm{kg}$. ${ }^{2}$ Nevertheless, dosing still poses a great problem, as there is no consensus on which is the best dose choice for different populations worldwide.

In a retrospective study performed in India, LAmB was administered to newly diagnosed LV-HIV-coinfected patients at a dose of $20-25 \mathrm{mg} / \mathrm{kg}$ total, achieving a cure rate at 1 - to 2-year follow-up of $85 \%$ and good tolerance..$^{53}$ By contrast, higher doses are necessary for treatment of VL-HIV coinfection in Ethiopia. ${ }^{54,55}$ Studies have been performed aiming to find better dose-efficacy combinations, mainly due the high LAmB costs, as well as combination therapy. Its main adverse drug effects are dose-dependent, highly toxic to endothelial cells, and thrombophlebitis during infusion, headache, fever, chills, asthenia, myalgia, arthralgia, emesis, and hypotension may occur, as well as hypokalemia during the treatment course. ${ }^{52}$ Due to its wide profile of adverse drug events, it should be administered in a hospital setting to provide monitoring and ready medical approaches for any complications. Liposomelipid complex preparations seem to present a better toxicity profile than conventional amphotericin B or pentavalent antimony, contributing to their higher clinical efficacy (Table 2). ${ }^{37}$

\section{Miltefosine}

Originally developed as an oral antineoplastic drug (class of alkylphosphocholine), miltefosine was shown to have leishmanicidal activity. It is the only available oral drug to treat leishmaniasis, targeting phosphatidylinositol 3 kinase-AktPKB signaling pathways to inhibit metastatic growth cells, and in Leishmania spp. it induces apoptosis, although exact mechanisms are still unknown. ${ }^{56,57}$ Its main limitations are teratogenicity and intense gastrointestinal side effects, like vomiting, diarrhea, and liver-enzyme elevation (mainly transaminases), requiring routine liver-enzyme monitoring. ${ }^{56,57}$ Laboratory resistance has been reported to be probably

Table 2 Main drugs used to treat visceral leishmaniasis in HIV-coinfected patients, according to dose and efficacy

\begin{tabular}{|c|c|c|c|}
\hline Treatment & Dosage & Efficacy/cure rate** & Reference \\
\hline Liposomal amphotericin B & $\begin{array}{l}6 \times 5 \mathrm{mg} / \mathrm{kg} / \text { day on alternate days - total } \\
\text { dose } 30 \mathrm{mg} / \mathrm{kg}\end{array}$ & $\begin{array}{l}\text { Parasitological response: } 59.5 \% \text { initial response; } \\
38 \% \text { effectiveness for visceral leishmaniasis } \\
\text { relapses }\end{array}$ & $\begin{array}{l}\text { Ritmeijer et al, } \\
201 I^{47}\end{array}$ \\
\hline Miltefosine & $100 \mathrm{mg} /$ day for 28 days & $\begin{array}{l}\text { Parastiological response: } 64 \% \text { initial response, with } \\
\text { short follow-up (median duration of disease-free } \\
\text { interval } 4-5 \text { months) }\end{array}$ & $\begin{array}{l}\text { Sindermann et al, } \\
2004^{59}\end{array}$ \\
\hline \multicolumn{4}{|l|}{ Combination therapy } \\
\hline $\begin{array}{l}\text { Liposomal amphotericin } \\
\text { plus miltefosine }\end{array}$ & $\begin{array}{l}30 \mathrm{mg} / \mathrm{kg} \text { divided in } 6 \text { equal dose on } \\
\text { alternate days }+50 \mathrm{mg} \text { twice or } 50 \mathrm{mg} \\
\text { once daily }\end{array}$ & $\begin{array}{l}\text { Eight relapses out } 100 \text { patients discharged after } \\
\text { intial cure }\end{array}$ & $\begin{array}{l}\text { Mahajan et al, } \\
2015^{69}\end{array}$ \\
\hline
\end{tabular}

Notes: *Contraindicated in HIV-infected patients due to toxicities and unacceptable death rate. **Different criteria to cure definition. 
related to its long half-life of 7 days. ${ }^{58}$ Studies including HIV patients are scarce. One performed in southern Europe with $L$. infantum included patients after first treatment had failed. Although a $64 \%$ cure rate was achieved, all relapsed. ${ }^{59}$ In Ethiopia, a randomized open-label trial concluded that miltefosine was safer but less effective than SSG in a highburden HIV population. ${ }^{44}$ Interestingly, in vitro studies have demonstrated that the drug reduced HIV1 replication in human dendritic and lymphocytes $\mathrm{CD} 4^{+}$cells, although no related clinical significance was demonstrated (Table 2). ${ }^{60}$

\section{Other drugs}

Paromomycin, an aminoglycoside antibiotic, was first identified as leishmanicidal in 1960s and had its first human trial in Kenya in $1980 .{ }^{61,62}$ Its poor absorption and intramuscular vial limited its use in clinical settings. Its mechanisms may be attributable to inhibition of protein synthesis and induction of abnormalities among mitochondrial parasite membrane. ${ }^{63}$ Furthermore, in vitro resistance is easily acquired, implying a potential threat to its clinical use. ${ }^{64}$ First used in India, pentamidine isethionate has limited clinical use because of its serious cardiac renal and gastrointestinal toxicities, in addition to variable efficacy. ${ }^{65,66}$ Action against Leishmania spp. seems to be via inhibition of the active transport system. ${ }^{65,66}$

\section{Combination therapy}

Relapse in coinfected patients is common, and thus, there is a need to provide a safe and effective treatment while protecting the limited drugs available from the development of resistance. With an aim to decrease development of acquired resistance, establish shorter, cheaper (considering that lowand middle-income countries are the most affected), and more efficacious treatment courses with fewer toxicities, consequently improving compliance and decreasing costs, combination therapy appears to be an attractive option and field to explore in the treatment paradigm. ${ }^{67,68}$ One retrospective analysis with a coinfected population in Bihar, India that received cumulative LAmB $30 \mathrm{mg} / \mathrm{kg}$ body weight and miltefosine $100 \mathrm{mg} /$ day for 14 days resulted in good tolerance and was safe and effective (Table 2). ${ }^{69}$

\section{Secondary prophylaxis}

Maintenance therapy is needed after effective initial treatment. ${ }^{52} \mathrm{~A}$ prospective randomized study evaluated the recurrence of VL using an amphoteric B lipid complex (3-5 mg/ $\mathrm{kg} /$ day) every 3 weeks for 12 months. In the group receiving secondary prophylaxis, the relapse was $22 \%$, whereas in the control group, relapse was $50 \%$, independent of the therapy used to treat the active disease. ${ }^{70}$ In addition, another study evaluated the efficacy of secondary prophylaxis with $4 \mathrm{mg}$ / $\mathrm{kg}$ /day for 5 days, followed by the same dose weekly for 5 weeks (ten doses total), and a disease-free rate of up to $80 \%$ was reported at 12 -month follow-up. ${ }^{71}$

Therefore, secondary prophylaxis with LAmB (3-4 $\mathrm{mg} / \mathrm{kg}$ ) every 2-4 weeks is recommended for prevention of VL relapse in HIV-coinfected individuals, since they have a high rate of annual recurrence. Other alternatives include the use of pentamidine isethionate monthly at $4 \mathrm{mg} / \mathrm{kg}{ }^{72}$ Initiation of HAART immediately following treatment for $\mathrm{VL}$ is recognized, with one study showing a $64 \%-66 \%$ reduction in mortality compared with those without ART. In addition, this approach can prevent VL relapses, as patients with lower $\mathrm{CD}^{+} \mathrm{T}$-cell counts are at increased risk, despite the use of secondary prophylaxis and effective initial treatment for VL. ${ }^{73}$

Miltefosine was used as maintenance therapy for three patients in Portugal, with a median time free of relapse of 20 months after 12, 14, and 21 months of maintenance therapy, but more studies must be designed to define this drug as an effective option. ${ }^{74}$ After patient immunofunction has recovered with HAART and VL seems quiescent with a $\mathrm{CD}^{+}$cell count maintained above 200 cells $/ \mu \mathrm{L}>6$ months, secondary prophylaxis should be interrupted. ${ }^{75,76}$

Additionally, HIV1 protease inhibitors have shown some inhibitory effect on Leishmania in vitro, yet in doses that would be unacceptable in human beings in vivo. As a backbone combination therapy, HAART with protease inhibitors would be preferable in this coinfected population, acting as a primary prophylaxis in asymptomatic Leishmania infection, an adjunctive therapy in those with clinical manifestations, or a maintenance therapy in those treatment-unresponsive. ${ }^{77}$

Natural products could be an option to treat visceral leishmaniasis; however, few clinical studies have been performed. Many compounds derived from natural products are toxic for Leishmania spp. Lignoids from Amazon Myristicaceae present biological activity against promastigote forms of Leishmania amazonensis, Leishmania braziliensis, and Leishmania chagasi. ${ }^{78}$ Polysaccharides from a variety of natural products have antileishmanial action. Among these are ones derived from arabinogalactan and isolated from Anadenanthera colubrina, which induces increased nitric oxide by macrophages. ${ }^{79}$ Alkaloids derived from Aspidosperma ramiflorum have shown activity against promastigotes. ${ }^{80}$ Also, alkaloids derived from marine sources exhibit excellent in vitro antileishmanial activity, inhibiting DNA synthesis. ${ }^{81}$ Others metabolites derived from natural sources 
have showing antileishmanial activity; however demonstration of these actions have been limited to in vitro studies. ${ }^{82}$

\section{Conclusion}

VL-HIV coinfection has spread in tropical areas; however, in some parts of the world, especially Europe, decreased LV-HIV coinfection has been observed. Mechanisms of HIV prevention, such as distribution of syringes to avoid sharing, was an important factor in this. Clearly, forms of HIV transmission are different in other regions, since in places where there is an increase in VL-HIV coinfection, the main route of HIV transmission is sexual and the transmission of VL vectorbased rather than sharing syringes, as demonstrated in Europe.

Some factors can contribute to outcomes of coinfected patients, mainly those related to host immunoresponse, as it is known that low CD4 T-lymphocyte counts and the absence of effective cellular response are predictors of lack of therapeutic response. However, new evidence suggests immunoactivation in a VL-HIV patient could be related to microbial translocation, producing lipopolysaccharides from Gram-negative bacteria. Clinical manifestation of VL in HIV-infected patient is similar to HIV-uninfected patients, although unusual manifestation is reported. Diagnosis of VL by serology in HIV-infected patients has low sensitivity, and parasitological methods are most used, due to their high sensitivity. Concerning relapse and mortality, VL-HIV patients have worse treatment response, and drug combinations could be an option associated with secondary prophylaxis and HAART.

\section{Acknowledgment}

This work was supported by FAPESP (Process FAPESP: 2016/03165-9).

\section{Author contributions}

JALL was responsible for structuring the manuscript, introduction, review, and final considerations, CHVM for writing about treatment, MAC for writing about diagnostics, and ITQ for writing about immunoresponse and clinical manifestation. All authors contributed toward data analysis, drafting and critically revising the paper, gave final approval of the version to be published, and agree to be accountable for all aspects of the work.

\section{Disclosure}

The authors report no conflicts of interest in this work.

\section{References}

1. World Health Organization [webpage on the Internet]. Leishmaniasis; 2018. Available from: http://www.who.int/news-room/fact-sheets/detail/ leishmaniasis. Accessed March 31, 2018.
2. World Heath Organization. Control of the Leishmaniases. Geneva: WHO; 2010.

3. World Health Organization [webpage on the Internet]. HIV/AIDS; 2018. Available from: http://www.who.int/news-room/fact-sheets/detail/ hiv-aids. Accessed March 31, 2018.

4. World Heath Organization. Manual on Case Management and Surveillance of the Leishmaniases in the WHO European Region. Geneva: WHO; 2017.

5. Diro E, Lynen L, Ritmeijer K, et al. Visceral leishmaniasis and HIV coinfection in East Africa. PLoS Negl Trop Dis. 2014;8(6):e2869.

6. Ministério da Saúde. Leishmaniose visceral [Visceral leishmaniasis]; 2017. Available from: http://portalms.saude.gov.br/saude-de-a-z/ leishmaniose-visceral. Accessed August 22, 2018. Portuguese.

7. Ferreira GR, Ribeiro JC, Filho AM, et al. Human competence to transmit Leishmania infantum to Lutzomyia longipalpis and the influence of human immunodeficiency virus infection. Am J Trop Med Hyg. 2018;98(1):126-133.

8. Echchakery M, Nieto J, Boussaa S, et al. Asymptomatic carriers of Leishmania infantum in patients infected with human immunodeficiency virus (HIV) in Morocco. Parasitol Res. 2018;117(4):1237-1244.

9. de Sousa-Gomes ML, Romero GA, Werneck GL. Visceral leishmaniasis and HIV/AIDS in Brazil: are we aware enough? PloS Negl Trop Dis. 2017;11(9):e0005772.

10. Cota GF, de Sousa MR, Rabello A. Predictors of visceral leishmaniasis relapse in HIV-infected patients: a systematic review. PLoS Negl Trop Dis. 2011;5(6):e1153.

11. Okwor I, Uzonna JE. The immunology of Leishmania/HIV co-infection. Immunol Res. 2013;56(1):163-171.

12. Lindoso JA, Cota GF, da Cruz AM, et al. Visceral leishmaniasis and HIV coinfection in Latin America. PLoS Negl Trop Dis. 2014;8(9):e3136.

13. Silva-Freitas ML, Cota GF, Machado-de-Assis TS, et al. Immune activation and bacterial translocation: a link between impaired immune recovery and frequent visceral leishmaniasis relapses in HIV-infected patients. PLoS One. 2016;11(12):e0167512.

14. Casado JL, Abad-Fernández M, Moreno S, et al. Visceral leishmaniasis as an independent cause of high immune activation, T-cell senescence, and lack of immune recovery in virologically suppressed HIV-1-coinfected patients. HIV Med. 2015;16(4):240-248.

15. Santos-Oliveira JR, Regis EG, Giacoia-Gripp CB, et al. Microbial translocation induces an intense proinflammatory response in patients with visceral leishmaniasis and HIV type 1 coinfection. $J$ Infect Dis. 2013;208(1):57-66.

16. Vallejo A, Abad-Fernández M, Moreno S, et al. High levels of $\mathrm{CD}^{+}$ CTLA- $4^{+} \mathrm{T}_{\text {reg }}$ cells and CCR5 density in HIV-1-infected patients with visceral leishmaniasis. Eur J Clin Microbiol Infect Dis. 2015;34(2):267-275.

17. Lindoso JA, Cunha MA, Queiroz IT, Moreira CH. Leishmaniasis-HIV coinfection: current challenges. HIV AIDS (Auckl). 2016;8:147-156.

18. Coutinho J, Santos FS, Ribeiro R, et al. Visceral leishmaniasis and leishmaniasis-HIV coinfection: comparative study. Rev Soc Bras Med Trop. 2017;50(5):670-674.

19. Lima IP, Müller MC, Holanda TA, et al. Human immunodeficiency virus/Leishmania infantum in the first foci of urban American visceral leishmaniasis: clinical presentation from 1994 to 2010. Rev Soc Bras Med Trop. 2013;46(2):156-160.

20. Ejara ED, Lynen L, Boelaert M, van Griensven J. Challenges in HIV and visceral Leishmania co-infection: future research directions. Trop Med Int Health. 2010;15(10):1266-1267.

21. Diro E, van Griensven J, Mohammed R, et al. Atypical manifestations of visceral leishmaniasis in patients with HIV in north Ethiopia: a gap in guidelines for the management of opportunistic infections in resource poor settings. Lancet Infect Dis. 2015;15(1):122-129.

22. Cota GF, de Sousa MR, de Mendonça AL, et al. Leishmania-HIV coinfection: clinical presentation and outcomes in an urban area in Brazil. PLoS Negl Trop Dis. 2014;8(4):e2816.

23. van Griensven J, Diro E, Leishmaniasis V. Visceral leishmaniasis. Infect Dis Clin North Am. 2012;26(2):309-322.

24. Srivastava P, Dayama A, Mehrotra S, Sundar S. Diagnosis of visceral leishmaniasis. Trans R Soc Trop Med Hyg. 2011;105(1):1-6. 
25. Cota GF, de Sousa MR, Nogueira BM, et al. Comparison of parasitological, serological, and molecular tests for visceral leishmaniasis in HIV-infected patients: a cross-sectional delayed-type study. Am J Trop Med Hyg. 2013;89(3):570-577.

26. Cota GF, de Sousa MR, Demarqui FN, Rabello A. The diagnostic accuracy of serologic and molecular methods for detecting visceral leishmaniasis in HIV infected patients: meta-analysis. PLoS Negl Trop Dis. 2012;6(5):e1665.

27. Gradoni L, Scalone A, Gramiccia M. HIV-Leishmania co-infections in Italy: serological data as an indication of the sequence of acquisition of the two infections. Trans R Soc Trop Med Hyg. 1993;87(1):94-96.

28. Cunningham J, Hasker E, Das P, et al. A global comparative evaluation of commercial immunochromatographic rapid diagnostic tests for visceral leishmaniasis. Clin Infect Dis. 2012;55(10):1312-1319.

29. Moreno EC, Melo MN, Lambertucci JR, et al. Diagnosing human asymptomatic visceral leishmaniasis in an urban area of the state of Minas Gerais, using serological and molecular biology techniques. Rev Soc Bras Med Trop. 2006;39(5):421-427.

30. Mukhtar M, Abdoun A, Ahmed AE, et al. Diagnostic accuracy of rK28-based immunochromatographic rapid diagnostic tests for visceral leishmaniasis: a prospective clinical cohort study in Sudan. Trans $R$ Soc Trop Med Hyg. 2015;109(9):594-600.

31. Boelaert M, El-Safi S, Hailu A, et al. Diagnostic tests for kala-azar: a multi-centre study of the freeze-dried DAT, rK39 strip test and KAtex in East Africa and the Indian subcontinent. Trans R Soc Trop Med Hyg. 2008;102(1):32-40.

32. Júnior WL, de Araújo PS, de Andrade LD, et al. Rapid tests and the diagnosis of visceral leishmaniasis and human immunodeficiency virus/ acquired immunodeficiency syndrome coinfection. Am JTrop Med Hyg. 2015;93(5):967-969.

33. Nuzum E, White F, Thakur C, et al. Diagnosis of symptomatic visceral leishmaniasis by use of the polymerase chain reaction on patient blood. J Infect Dis. 1995;171(3):751-754.

34. Khatun M, Alam SM, Khan AH, et al. Novel PCR primers to diagnose visceral leishmaniasis using peripheral blood, spleen or bone marrow aspirates. Asian Pac J Trop Med. 2017;10(8):753-759.

35. Moore EM, Lockwood DN. Treatment of visceral leishmaniasis. J Glob Infect Dis. 2010;2(2):151-158.

36. den Boer M, Davidson RN. Treatment options for visceral leishmaniasis. Expert Rev Anti Infect Ther. 2006;4(2):187-197.

37. Frézard F, Demicheli C, Ribeiro RR. Pentavalent antimonials: new perspectives for old drugs. Molecules. 2009;14(7):2317-2336.

38. Croft SL, Yardley V. Chemotherapy of leishmaniasis. Curr Pharm Des. 2002;8(4):319-342.

39. No JH. Visceral leishmaniasis: revisiting current treatments and approaches for future discoveries. Acta Trop. 2016;155:113-123.

40. Tiwari N, Gedda MR, Tiwari VK, et al. Limitations of current therapeutic options, possible drug targets and scope of natural products in control of leishmaniasis. Mini Rev Med Chem. 2018;18(1): 26-41.

41. Pintado V, López-Vélez R. HIV-associated visceral leishmaniasis. Clin Microbiol Infect. 2001;7(6):291-300.

42. Cota GF, de Sousa MR, Fereguetti TO, Rabello A. Efficacy of antiLeishmania therapy in visceral leishmaniasis among HIV infected patients: a systematic review with indirect comparison. PLoS Negl Trop Dis. 2013;7(5):e2195.

43. Diro E, Lynen L, Mohammed R, et al. High parasitological failure rate of visceral leishmaniasis to sodium stibogluconate among HIV co-infected adults in Ethiopia. PLoS Negl Trop Dis. 2014;8(5):e2875.

44. Ritmeijer K, Dejenie A, Assefa Y, et al. A comparison of miltefosine and sodium stibogluconate for treatment of visceral leishmaniasis in an Ethiopian population with high prevalence of HIV infection. Clin Infect Dis. 2006;43(3):357-364.

45. Mengistu G, Ayele B. Visceral leishmaniasis and HIV co-infection in patients admitted to Gondar University Hospital, northwest Ethiopia. Ethiop J Health Dev. 2007;21:53-60.
46. Ritmeijer K, Veeken H, Melaku Y, et al. Ethiopian visceral leishmaniasis: generic and proprietary sodium stibogluconate are equivalent: HIV co-infected patients have a poor outcome. Trans $R$ Soc Trop Med Hyg. 2001;95(6):668-672.

47. Ritmeijer K, ter Horst R, Chane S, et al. Limited effectiveness of highdose liposomal amphotericin B (AmBisome) for treatment of visceral leishmaniasis in an Ethiopian population with high HIV prevalence. Clin Infect Dis. 2011;53(12):e152-e158.

48. Perry MR, Prajapati VK, Menten J, et al. Arsenic exposure and outcomes of antimonial treatment in visceral leishmaniasis patients in Bihar, India: a retrospective cohort study. PLoS Negl Trop Dis. 2015;9(3):e0003518

49. Adler-Moore J, Proffitt RT. AmBisome: liposomal formulation, structure, mechanism of action and pre-clinical experience. J Antimicrob Chemother. 2002;49(Suppl 1):21-30.

50. Zijlstra EE. Visceral leishmaniasis: a forgotten epidemic. Arch Dis Child. 2016;101(6):561-567.

51. Ministério da Saúde. Manual de Vigilância y Control de la Leishmaniose Visceral. Brasília: Ministério da Saúde; 2014.

52. Monge-Maillo B, López-Vélez R. Treatment options for visceral leishmaniasis and HIV coinfection. AIDS Rev. 2016;18(1):32-43.

53. Sinha PK, van Griensven J, Pandey K, et al. Liposomal amphotericin B for visceral leishmaniasis in human immunodeficiency virus-coinfected patients: 2-year treatment outcomes in Bihar, India. Clin Infect Dis. 2011;53(7):e91-e98.

54. Balasegaram M, Ritmeijer K, Lima MA, et al. Liposomal amphotericin $\mathrm{B}$ as a treatment for human leishmaniasis. Expert Opin Emerg Drugs. 2012;17(4):493-510.

55. Diro E, Lynen L, Ritmeijer K, et al. Visceral leishmaniasis and HIV coinfection in East Africa. PLoS Negl Trop Dis. 2014;8(6):e2869.

56. Dorlo TP, Balasegaram M, Beijnen JH, de Vries PJ. Miltefosine: a review of its pharmacology and therapeutic efficacy in the treatment of leishmaniasis. J Antimicrob Chemother. 2012;67(11):2576-2597.

57. Paris C, Loiseau PM, Bories C, Bréard J. Miltefosine induces apoptosislike death in Leishmania donovani promastigotes. Antimicrob Agents Chemother. 2004;48(3):852-859.

58. Mishra J, Singh S. Miltefosine resistance in Leishmania donovani involves suppression of oxidative stress-induced programmed cell death. Exp Parasitol. 2013;135(2):397-406.

59. Sindermann H, Engel KR, Fischer C, Bommer W. Oral miltefosine for leishmaniasis in immunocompromised patients: compassionate use in 39 patients with HIV infection. Clin Infect Dis. 2004;39(10):1520-1523.

60. Garg R, Tremblay MJ. Miltefosine represses HIV-1 replication in human dendritic cell/T-cell cocultures partially by inducing secretion of type-I interferon. Virology. 2012;432(2):271-276.

61. Moskalenko NI, Pershin GN. [Comparative study of the chemotherapeutic effect of paromomycin and monomycin in experimental cutaneous leischmaniasis in albino mice]. Farmakol Toksikol. 1966;29(1):90-94. Russian.

62. Chunge CN, Owate J, Pamba HO, Donno L. Treatment of visceral leishmaniasis in Kenya by aminosidine alone or combined with sodium stibogluconate. Trans R Soc Trop Med Hyg. 1990;84(2):221-225.

63. Chawla B, Jhingran A, Panigrahi A, Stuart KD, Madhubala R. Paromomycin affects translation and vesicle-mediated trafficking as revealed by proteomics of paromomycin-susceptible-resistant Leishmania donovani. PLoS One. 2011;6(10):e26660.

64. Hendrickx S, Boulet G, Mondelaers A, et al. Experimental selection of paromomycin and miltefosine resistance in intracellular amastigotes of Leishmania donovani and L. infantum. Parasitol Res. 2014;113(5): 1875-1881.

65. Singh N, Kumar M, Singh RK. Leishmaniasis: current status of available drugs and new potential drug targets. Asian Pac J Trop Med. 2012;5(6):485-497.

66. Kuhlencord A, Maniera T, Eibl H, Unger C. Hexadecylphosphocholine: oral treatment of visceral leishmaniasis in mice. Antimicrob Agents Chemother. 1992;36(8):1630-1634. 
67. Bern C [webpage on the Internet]. Visceral leishmaniasis: treatment; 2018. Available from: https://www.uptodate.com/contents/visceralleishmaniasis-treatment. Accessed July 30, 2018.

68. Monge-Maillo B, López-Vélez R. Miltefosine for visceral and cutaneous leishmaniasis: drug characteristics and evidence-based treatment recommendations. Clin Infect Dis. 2015;60(9):1398-1404.

69. Mahajan R, Das P, Isaakidis P, et al. Combination Treatment for visceral leishmaniasis patients coinfected with human immunodeficiency virus in India. Clin Infect Dis. 2015;61(8):1255-1262.

70. López-Vélez R, Videla S, Márquez M, et al. Amphotericin B lipid complex versus no treatment in the secondary prophylaxis of visceral leishmaniasis in HIV-infected patients. J Antimicrob Chemother. 2004;53(3):540-543.

71. Molina I, Falcó V, Crespo M, et al. Efficacy of liposomal amphotericin B for secondary prophylaxis of visceral leishmaniasis in HIV-infected patients. J Antimicrob Chemother. 2007;60(4):837-842.

72. Diro E, Ritmeijer K, Boelaert M, et al. Use of pentamidine as secondary prophylaxis to prevent visceral leishmaniasis relapse in HIV infected patients, the first twelve months of a prospective cohort study. PLoS Negl Trop Dis. 2015;9(10):e0004087.

73. Burza S, Mahajan R, Sinha PK, et al. Visceral leishmaniasis and HIV co-infection in Bihar, India: long-term effectiveness and treatment outcomes with liposomal amphotericin B (AmBisome). PLoS Negl Trop Dis. 2014;8(8):e3053.

74. Marques N, Sá R, Coelho F, et al. Miltefosine for visceral leishmaniasis relapse treatment and secondary prophylaxis in HIV-infected patients. Scand J Infect Dis. 2008;40(6-7):523-526.
75. Soriano V, Dona C, Rodríguez-Rosado R, Barreiro P, González-Lahoz J. Discontinuation of secondary prophylaxis for opportunistic infections in HIV-infected patients receiving highly active antiretroviral therapy. AIDS. 2000;14(4):383-386.

76. Berenguer J, Cosín J, Miralles P, López JC, Padilla B. Discontinuation of secondary anti-Leishmania prophylaxis in HIV-infected patients who have responded to highly active antiretroviral therapy. AIDS. 2000;14(18):2946-2948.

77. van Griensven J, Diro E, Lopez-Velez R, et al. HIV-1 protease inhibitors for treatment of visceral leishmaniasis in HIV-co-infected individuals. Lancet Infect Dis. 2013;13(3):251-259.

78. Morais SK, Teixeira AF, Torres ZE, et al. Biological activities of lignoids from Amazon Myristicaceae species: Virola michelii, V. mollissima, V. pavonis and Iryanthera juruensis. J Braz Chem Soc. 2009;20(6): 1110-1118.

79. Kangussu-Marcolino MM, do Rosário MM, Noseda MD, et al. Acid heteropolysaccharides with potent antileishmanial effects. Int $\mathrm{J}$ Biol Macromol. 2015;81:165-170.

80. Tanaka JC, da Silva CC, Ferreira IC, Machado GM, Leon LL, de Oliveira AJ. Antileishmanial activity of indole alkaloids from Aspidosperma ramiflorum. Phytomedicine. 2007;14(6):377-380.

81. Shyaula SL, Tamang T, Ghouri N, et al. Antileishmanial diterpenoid alkaloids from Aconitum spicatum (Bruhl) Stapf. Nat Prod Res. Epub 2015 Nov 30.

82. Tiwari N, Gedda MR, Tiwari VK, et al. Limitations of current therapeutic options, possible drug targets and scope of natural products in control of leishmaniasis. Mini Rev Med Chem. 2018;18(1):26-41.
HIV/AIDS - Research and Palliative Care

\section{Publish your work in this journal}

HIV/AIDS - Research and Palliative Care is an international, peerreviewed open access journal focusing on advances in research in HIV its clinical progression and management options including antiviral treatment, palliative care and public healthcare policies to control viral spread. The journal is included in PubMed. The manuscript man-

\section{Dovepress}

agement system is completely online and includes a very quick and fair peer-review system, which is all easy to use. Visit http://www.dovepress. com/testimonials.php to read real quotes from published authors. 